\title{
ANALISIS JENIS-JENIS DAN FUNGSI PANTUN DALAM BUKU MANTRA SYAIR DAN PANTUN DI TENGAH KEHIDUPAN DUNIA MODERN KARYA KORRIE LAYUN RAMPAN
}

\author{
Trisnawati \\ Trisna_wati39@yahoo.com \\ RA Pertiwi Mataram
}

\begin{abstract}
ABSTRAK
Permasalahan yang akan diteliti dalam penelitian yaitu"Analisis Jenis-Jenis dan Fungsi Pantun dalam Buku Mantra Syair dan Pantun di Tengah Kehidupan Dunia Modern Karya Korrie Layun Rampan"pantun merupakan puisi Melayu lama asli Indonesia yang terdiri dari sampiran dan isi ab-a-b. Tujuan penelitian ini adalah untuk mengetahui tentang isi pantun dan mendeskripsikan, jenis-jenis dan fungsi pantun yang terdapat dalam buku Mantra Syair dan Pantun di Tengah Kehidupan Dunia Modern Karya Korrie Layun Rampan. Metode yang digunakan dalam penelitian ini adalah metode deskriptif. Teknik pengumpulan data yang digunakan teknik pustaka, sedangkan teknik analisis data menggunakan teknik analisis isi (content analysis). Berdasarkan hasil penelitian dan pembahasan dapat disimpulkan bahwa jenis-jenis pantun berdasarkan isinya dalam buku“ Mantra Syair dan Pantun di Tengah Kehidupan Dunia Modern Karya Korrie Layun Rampan tahun 2014" terdapat beberapa jenis pantun yaitu pantun muda-mudi, pantun orang tua, pantun teka teki, pantun rindu, pantun nasihat yang semuanya berjumlah 64 buah pantun. Pantun muda-mudi sebanyak 9 buah, pantun orang tua sebanyak 14 buah, pantun teka teki sebanyak 10 buah, pantun rindu sebanyak 15 buah, dan pantun nasihat sebanyak 16 buah.
\end{abstract}

Kata Kunci: Pantun, Buku Mantra Syair dan Pantun di Tengah Kehidupan Dunia Modern Karya Korrie Layun Rampan

\section{ANALYSIS OF TYPES AND FUNCTIONS OF PANTUN IN THE MANTRA SYAIR AND PANTUN BOOKS IN THE MIDDLE OF LIFE MODERN WORKS OF RAMPAN WOOD KORRIE WORKS}

\begin{abstract}
The problem to be examined in this research is "Analysis of Types and Functions of Pantun in the Poetry and Poetry Mantra Book in the Middle of Modern World Life by Korrie Layun Rampan" pantun is an old Indonesian original Malay poem consisting of sampels and contents of a-b-a-b. The purpose of this study is to find out about the content of rhymes and describe the types and functions of rhymes contained in the Mantra and Poetry Mantra book in the Middle of Modern World Life by Korrie Layun Rampan. The method used in this research is descriptive method. Data collection techniques used were library techniques, while data analysis techniques used content analysis techniques. Based on the results of research and discussion it can be concluded that the types of rhymes based on their contents in the book "Poetry Mantra and Rhymes in the Middle of Modern World Life by Korrie Layun Rampan in 2014" there are several types of rhymes namely rhymes of young people, rhymes of parents, rhymes rhymes, rhymes longing, rhyme of advice which all numbered 64 rhymes. 9 poems of young people, rhymes of 14 parents, rhymes of 10 pieces, rhymes of 15 pieces, and rhymes of 16 pieces.
\end{abstract}

Trisnawati

Keywords: Pantun, Poetry and Pantun Mantra Books in the Middle of Modern World Life by Korrie Layun Rampan 


\section{A. PENDAhuluan}

Sastra atau kesusastraan merupakan jenis tulisan yang memiliki arti dan keindahan tertentu bagi orang yang membaca atau mendengarkannya. Karya sastra lama seperti puisi terikat, pantun, syair, hikayat, legenda, mite dan dongeng sedangkan kalau sastra modern puisi bebas, cerpen, novel, drama dan esai. Sugiarto (2015:3) mengatakan bahwa, "Pantun berasal dari bahasa Jawa, yaitu pantun atau pari. Baik pantun maupun pari sama-sama berarti dalam bahasa Indonesia (Melayu). Menurut Sugiarto (2015:6) menyatakan, "Pantun merupakan puisi Indonesia klasik yang paling banyak diteliti oleh pakar sastra, baik dari Indonesia maupun luar negeri

Kosasih (2013:198), mengemukakan ciri-ciri pantun, yaitu tiap baris terdiri atas 8 sampai 12 suku kata, dua baris pertama disebut sampiran dan dua baris berikutnya disebut isi pantun, mementingkan rima akhir dengan pola a-b-a-b-b. Menurut Waridah ( 2014:34), pantun memiki ciri-ciri, yaitu: rima akhir setiap baris adalah a-b-a-b, baris pertama dan kedua merupakan sampiran, baris ketiga dan keempat merupakan isi. Menurut isinya, pantun dapat dibedakan atas beberapa pantun. Kosasih (2013:81) menyatakan jenis pantun berdasarkan isinya pantun remaja atau dewasa, pantun orang tua. Menurut Gani (2007:301) jenis pantun berdasarkan isinya, pantun jenaka, pantun perkenalan, pantun berkasih-kasihan, pantun nasihat, pantun agama, pantun bersuka cita. Menurut Rampan (2014:115), mantra adalah puisi tertua dalam sastra indonesia lama. Pada awalnya, mantra bukanlah karya sastra.

Sekarang banyak orang yang kurang tertarik dalam membaca pantun dan membuat pantun karena pandangan mereka membaca sangat membosankan. Peneliti ingin memberi sedikit pandangan bahwa membaca dan membuat pantun itu sangat menyenangkan dan bisa mengetahui makna yang disampaikan didalam setiap pantun tersebut, bisa menambah pengetahuan, informasi yang aktual, dan bisa memberikan hiburan bagi pembaca. Selain menarik pembaca untuk membaca buku bisa juga langsung dalam melestarikan karya sastra lama. Contohnya dalam buku Mantra Syair dan Pantun di Tengah Kehidupan Dunia Modern Karya Korrie Layun Rampan, didalam buku karya Korrie Layun Rampan tahun 2014 terdapat bermacam-macam pantun dengan berbagai jenis pantun sesuai dengan pantun yang disampaikan. Peneliti berharap dengan adanya penelitian ini minat seorang dalam membaca dan melestarikan pantun semakin meningkat.

\section{B. METODOLOGI PENELITIAN}

Metode adalah cara yang dipergunakan seorang peneliti di dalam usaha memecahkan masalah yang diteliti. Metode yang digunakan dalam penelitian ini adalah metode deskriptif. Metode deskriptif adalah metode yang memberikan beberapa kemungkinan untuk memecahkan masalah yang aktual dengan jalan mengumpulkan data, menyusun atau mengklasifikasinya, menganalisis, atau mengimplementasikan (Mahsun, 2011:23). Sumber data dalam penelitian ini terbagi menjadi dua bagian, yaitu data primer dan data sekunder. Data primer yang digunakan dalam penelitian ini adalah teks. Teks yang digunakan adalah buku "Mantra Syair dan Pantun di 
Tengah Kehidupan Dunia Modern Karya Korrie Layun Rampan" cetakan ke-1 yang diterbitkan oleh penerbit Yrama Widya Bandung tahun 2014. Sumber data sekunder berupa artikel-artikel dan kutipan-kutipan dari buku-buku teori yang mendukung penelitian ini. Untuk mengumpulkan data, penulis menggunakan bahan pustaka yaitu dengan menganalisis teks pantun yang bermakna lugas dan kias, dari lima jenis pantun yang terpilih. Pada analisis ini peneliti, membaca kemudian mencatat dukomen-dukomen yang diambil dari data primer yang berkaitan dengan masalah dan tujuan penelitian. Datanya berupa pantun yang terdapat dalam buku "Mantra Syair dan Pantun di Tengah Kehidupan Dunia Modern Karya Korrie Layun Rampan” tahun 2014 sebanyak satu buku yang terdapat delapan belas jenis pantun. Penulis membatasi hanya lima jenis pantun saja yang akan dianalisis, sistem pengumpulan data dari populasi sebanyak delapan belas pantun yang ada di dalam buku"Mantra Syair dan Pantun di Tengah Kehidupan Dunia Modern Karya Korrie Layun Rampan tahun 2014" dengan cara diundi dengan pemberian nomor di setiap pantun bagi nomor yang keluar maka itulah pantun yang akan dianalisis.

\section{HASIL PENELITIAN DAN PEMBAHASAN}

1. Pantun Muda-Mudi

\section{Pantun 1}

Buah durian berduri-duri Bila masak tentulah gugur Sudah berbulan kunanti-nanti Adik mengelak hatiku hancur Isi

\section{Pantun 2}

Ulam bukan sembarang ulam Ulamnya dibawa anak penggalas Demam bukan sembarang demam Demam cinta tak terbalas

\section{Pantun 3}

Gugur buah di pagi hari Ada masak ada yang muda Hancur sudah hatiku ini Cinta ditolak begitu saja

\section{Pantun 4}

Buah perindu di Bukit Siguntang Sejak dahulu berhujan panas Tubuhku layu sakit telentang Karena cintaku tiada berbalas

\section{Pantun 5}

Ampas kelapa dibuang orang Jauh ke sungai dimakan ika Lemas anggota remuklah tulang Kasih tak sampai binasa badan

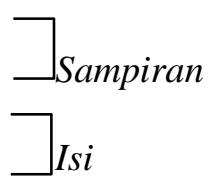

\section{Pantun 6}

Anak elang mati terkejut Hilang campak ke dalam paya Awaklah sayang hati terpaut Orang menolak apalah daya
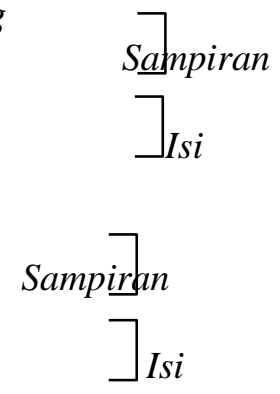

\section{Pantun 7}


Asap api dari seberang Dibawa angin ke tengah laut Hasrat hati memetik kembang Rupanya kasih tiada besrambut Sampiran
]$_{I s i}$

\section{Pantun 8}

Belum duduk sudah berdiri Manakah orang dapat bicara Belum ditengok sudah lari Manakah sempat kita bercinta

\section{Pantun 9}

Asap api nampak menjulang Petang hari barulah reda Hasrat hati hendak meninang Orang tak sudi undurlah hamba

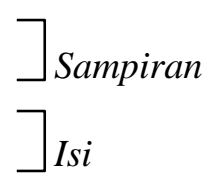

Pantun di atas menceritakan jenis-jenis pantun berdasarkan isinya yaitu "Pantun Muda Mudi" Pantun di atas berisi tentang perasaan seorang yang sangat sedih dan patah hati karena cintanya tidak terbalas. Bentuk pantun berdasarkan barisan yaitu "Pantun Biasa" karena didalamnya terdiri empat baris tiap bait. Pantun tersebut berfungsi untuk berkasih-kasihan. Rima dalam pantun di atas bersajak a-b-a-b.

\section{Pantun Orang Tua}

\section{Pantun 1}

Asam kandis asam gelugur Ketiga asam si riang-riang Menangis mayat di dalam kubur Teringat badan tak sembahyang

\section{Pantun 2}

Pohon di kebun habis berbuah

Disambut masak buah rumbiga

Mohonkan ampun dosa yang sudah

Hendak masuk dalam surga

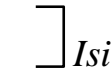

\section{Pantun 3}

Mengkudu buahnya pahit

Buah kepayang dingin airnya

Biar ilmu setinggi langit

Kalau tak sembahyang apa gunannya

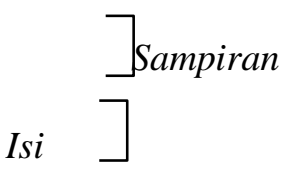

\section{Pantun 4}

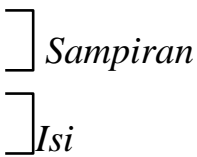

Bunga kenangaan di atas kubur

Pucuk sari pandan Jawa

Apa guna sombong takabur

Rusak hati badan binasa

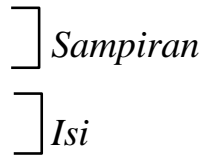

\section{Pantun 5}

Sandarkan galah pada pohon

Kayu tersandar berapit dua

Sampiran

Kepada Allah tempat bermohon

Kalau kita sandarkan nyawa

Isi

\section{Pantun 6}

Pangkal berbelit di pohon jarak

Jarak nn tumbuh tepi serambi

Jangan dibuat dilarang syarak

Itulah perbuatan yang diibenci Nabi

Isi ] 


\section{Pantun 7}

Kera banyak tengah berhimpun Sandarkan galah pada pohon Segeralah kita minta ampun Kepada Allah tempat bermohon

\section{Pantun 8}

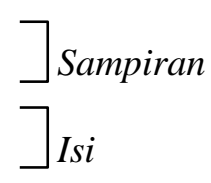

Bendahara datuk seri paduka Memerintah kota dan negeri Sengsara masuk dalam neraka Hendaklah kita ingatkan diri

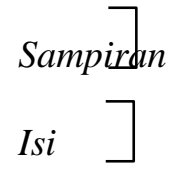

Pantun 9

Sungguh indah pintu dipahat Burung puyuh di atas dahan Kalau hidup hendak selamat Taat selalu perintah tuhan Sdmpiran $\dashv$ Isi

\section{Pantun 10}

Batang keranji kalau diukir Batang nangka dibelah-belah Seberang janji kalau mungkir Datang murka daripada Allah

Pantun 11

Bungan mawar bunga melati Kala dicium harum baunya Banyak cara sembuhkan hati Baca Quran pahamkan maknanya

Isi

\section{Pantun 12}

Batang nangka dibelah-belah Buah pandan jatuh tercebut Jika datang murka Allah Remuklah badn dalam kubur

\section{Sdmpiran}

Salmpiran

Isi

\section{Pantun 13}

Tiap napas tidaklah kekal Siapkan bekal menjelang wafat Tarulah Nabi siapkan bekal Dengan sebar ilmu manfaat

\section{Is]}

\section{Pantun 14}

Colok dipotong dengan sekin

Sekin waja buatan Jawa

Hendaklah diturut dengan yakin

Yakin di hati selamatlah nyawa

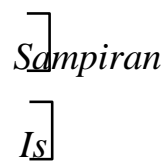

Pantun di atas menceritakan jenis-jenis pantun berdasarkan isinya yaitu "Pantun Orang Tua" Bentuk pantun berdasarkan barisan yaitu "Pantun Biasa" karena didalamnya terdiri empat baris tiap bait. Pantun di atas berfungsi untuk memberikan nasihat. Rima dalam pantun di atas bersajak a-b-a-b. Pemilihan kata yang digunakan dalam pantun di atas bermakn denotasi atau makna lugas.

\section{Pantun Teka-Teki}

\section{Pantun 1}

Kalau puan, puan cerana 
Ambil gelas di dalam peti

Kalau tuan bijak laksana

Binatang apa tanduk di kaki

\section{Pantun 2}

Bulan suci bulan Ramadhan

Orang ratib di bulan mulia

Aku bersisik bukannya ikan

Berpayung aku bukannya raja

\section{Pantun 3}

Buah budi bedara mengkal Masak sebiji di tepi pantai Hilang budi bicara akal Buah apa tidak bertangkai?

\section{Pantun 4}

Burung nari burung dara Terbang ke sisi taman kesayangan Cobalah cari wahai saudara

Makin diisi makin ringan

\section{Pantun 5}

Habislah buah pisang nangka Dijual ke pasar di tengah kota Ada beliung di kepala jantannya Seperti sarang madu layaknya

\section{Pantun 6}

Ada sebiji roda pedati

Bentuknya bulat dari besi

Bermain diikat sekuat hati

Dilempar hidup dipegang mati

\section{Pantun 7}

Di musim buah aku dicari

Bundar aku sebagai buahannya

Buahku buahan berduri

Dibuat tempoyak aku biasanya

\section{Pantun 8}

Biduk sekunar dari darat

Penuh berisi asam cuka

Makan di laut muntah di darat

Apakah itu coba terka

\section{Pantun 9}

Terendak bentan lalu dibeli

Pakaiammya turun ke bawah

Kalaulah tuan bijak bestari

Binatang apa kepada di bawah

Pantun 10

Buat apa bersedih hati

Menanti kawan belum tiba

Bila Tuan bijak bestari

Kuda apa berkaki dua

Pantun di atas menceritakan jenis-jenis pantun berdasarkan isinya yaitu "Pantun Orang

Teka-teki" Karena berisi senda gurau dan membuat pendengar untuk berfikir. Bentuk pantun berdasarkan barisan yaitu "Pantun Biasa" karena didalamnya terdiri empat baris satu bait. Pantun di
Sampiran

Is]

Sampiran

Isi ]

Sampirdn

Isi ]

Sampirau

Isi ]

\section{Sampiran}

$I s i$

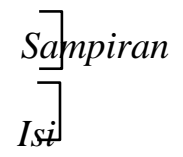

Sampiran

Isi ]

Sampirah

Isi ]
Sampiran

Isi ]

Isi ] 
atas berfungsi untuk dijawab oleh orang yang mendengarnya dan membuat orang penasaran akan jawabannya.

\section{Pantun Rindu}

\section{Pantun 1}

Dari Sendawar ke Samarinda Naik kapal menghiliri Mahakam Hatiku gentar tinggalkan adinda Diliputi terus rindu dendam

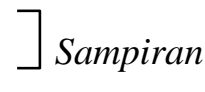

Isi $]$

\section{Pantun 2}

Selimat di ujung balai

Tempat acara dukun Rikam Sampirdn

Apa pengikat tuan pakai

Menjadi rindu siang malam Isi

\section{Pantun 3}

Mabuk buaya karena kesumba

Destar sebalik ditundungkan Sampiran ]

Mabuk hamba karena bercinta

Sebagai penyakit ditanggukan

\section{Pantun 4}

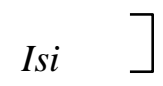

Lancang pulau dari selatan Angin bertiup dari utara Sampiran Hilang pulau lenyap daratan Namun laut berombak jua

Isi $]$

\section{Pantun 5}

Sehari-hari menghadap ratu

Senangnya bukan alang-kepalang

Cinta berahi sudah bersatu

Seperti dahaga lepas kerongkongan Isi ]

\section{Pantun 6}

Guruh petus penuba limbat Ikan lumba berenang-renang Sampiran _

Tujuh ratus carikan obat

Badan berjumpa maka senang

Isi $]$

\section{Pantun 7}

Naik ke bukit bermain angin

Pandan berbuah akan permata

Sakit sungguh berpisah main

Makan berkuah air mata

\section{Sampiren}

Pantun 8

Kalau baik merendam selasih

Pantang merendam biji labu

Kalau adik merendam kasih

Abang pun karam menahan rindu

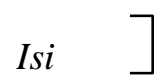

Baik sunguh pergi berburu

Dapat pelanduk dua tiga

Adik jauh hatiku rindu

Penat duduk menanti berita

Sampiran

Pantun 10

Isi ]

Roboh lantai titian kijang 
Anak rusa makan padi

Tubuh besar dadanya bidang

Tempat adinda bersandar mati

\section{Pantun 11}

Buluh perindu dibuat suling

Bunyinya merdu mendayu-dayu Menahan rindu badanku kering

Dinda tak mau mengambil tahu

Pantun 12

Ngilu gigiku makan jambu Makan langsat sisa tupai Ingin hatiku hendak bertemu Lepas puasa barunya sampai

\section{Pantun 13}

Dari pulau menjala ikan Dapat pari dibuat pindang Hati risau tiada bertahan Mabuk menanti adik datang

Pantun 14

Bungan melur cempaka biru Bunga rampai di dalam puan Tujuh malam semalam rindu Belum sampai padamu tuan

\section{Pantun 15}

Bungan rampai di dalam puan

Ruku-ruku dari pernggit

Belum sampai kepadamu tuan

Rindu saya bukan sedikit

Pantun di atas menceritakan jenis-jenis pantun berdasarkan isinya yaitu "Pantun Orang
Sampiran

Sampiran

Isi $]$

Sampirah

Isi ]
Isi ]
Sampiran

Isi ]

Sempiran

Isti
Sampiran

Isi ]

Muda". Bentuk pantun berdasarkan barisan yaitu "Pantun Biasa" karena didalamnya terdiri empat baris tiap bait. Pantun di atas berfungsi untuk berkasih-kasihan. Rima dalam pantun di atas bersajak $a-b-a-b$.

\section{Pantun Nasihat}

\section{Pantun 1}

Kulit lembu celupkan samak Mari dibuat tapak kasut Harta dunia janganlah tamak Kalau mati tidak mengikut

\section{Pantun 2}

Kayu bakar dibuat arang Arang dibakar memanaskan diri Jangan mudah menyalahkan orang Cermin muka lihat sendiri<smiles>CC[C@H](C)CC[AlH2]</smiles>

Pantun 3

Berburu ke padang datar Dapat rusa beelang kaki Berguru kepalang ajar Bagai bunga kembang tak jadi

\section{Pantun 4}

Sampirah

Isi $]$

Sampiran

Isi $]$ 
Pulau pandan jauh di tengah

Di balik pulau angsa dua

Hancur badan dikandung tanah

Budi baik terkenang jua

Sampiran

Isi

\section{Pantun 5}

Buah cempedak bentuknya bujur

Sangat disukai oleh semua

Jika kita bersikap jujur

Hidup kita dipandang mulai

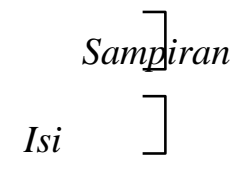

Pantun 6

Keluk paku asam belimbing

Tempuruk lenggang-lenggangkan

Anak dipangku, kemenakan dibimbing

Orang kampung pertengganggkan

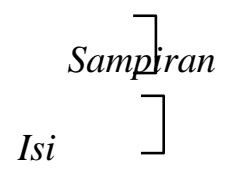

\section{Pantun 7}

Anak ayam turun sepuluh

Mati satu tinggal sembilan

Sampirah

tuntut ilmu bersungguh-sungguh

satu jangan ketinggalan Isi

\section{Pantun 8}

si ]

kemuning di tengah balai

bertumbuh terus semakin tinggi

berunding dengan orang tak pandai

bagaikan alu pencukil duri

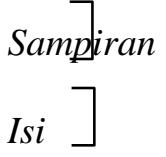

\section{Pantun 9}

rama-rama si kumbang janti khatib Endang pulang berkuda patah tumbuh hilang bergati pusaka tinggal begitu juga

\section{Pantun 10}

Air meluruk ke tepian mandi Kembang berseri bunga seduduk Indah diturut kajian padi

Semakin berisi semakin merunduk

\section{Pantun 11}

Sampiran

$$
\text { Isi }]
$$

Sampiran

Isi ]

Anak pelanduk dalam perigi

Ikan belanak masuk ke belat

Jangan duduk berhati dengki

Aduhai anak hendaklah ingat

\section{Pantun 12}

Tengah hari pergi mengail

Dapat seekor ikan tenggiri

Jangan amalkan sikap bakhil

Akan merusak diri sendiri

Pantun 13

Bunga anggrek pohon benalu

Buah berangan dari Jawa

Kalau cerdikk pikir dahulu

Jangan diri dapat kecewa

\section{Sampirdn}

Isi

Sampirdn

Isi

Sampirah

Isi

\section{Pantun 14}

Batang ketumbar berdahan-dahan 
Kelapa jatuh ke tepi bangsal Biar sabar dengan perlahan Siapa gopoh nanti menyesal

\section{Pantun 15}

Asal kapas menjadi benang

Dari lepas jangan dikenang

Barang lepas jangan dikenang

Kini jadi milik orang lain

\section{Sampiran}

Isi $]$

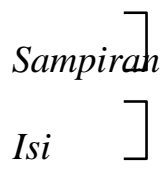

\section{Pantun 16}

Berakit-rakit ke hulu

Berenang-renang ke tepian Sampiran

Nersakit-sakit dahulu

Bersenang-senang kemudian Isi

Pantun di atas menceritakan jenis-jenis pantun berdasarkan isinya yaitu "Pantun Orang

Tua" Bentuk pantun berdasarkan barisan yaitu "Pantun Biasa" karena didalamnya terdiri empat baris tiap bait. Pantun di atas berfungsi untuk memberikan nasihat. Rima dalam pantun di atas bersajak a-b-a-b.

Berdasarkan analisis jenis-jenis dan fungsi pantun dalam buku “ Mantra Syair dan Pantun di Tengah Kehidupan Dunia Modern Karya Korrie Layun Rampan tahun 2014" terdapat beberapa jenis pantun yaitu pantun muda-mudi, pantun orang tua, pantun teka teki, pantun rindu, pantun nasihat yang semuanya berjumlah 64 buah pantun. Pantun muda-mudi sebanyak 9 buah, pantun orang tua sebanyak 14 buah, pantun teka teki sebanyak 10 buah, pantun rindu sebanyak 15 buah, dan pantun nasihat sebanyak 16 buah.

\section{SIMPULAN}

Berdasarkan hasil penelitian dan pembahasan dapat disimpulkan bahwa jenis-jenis pantun berdasarkan isinya dalam buku " Mantra Syair dan Pantun di Tengah Kehidupan Dunia Modern Karya Korrie Layun Rampan tahun 2014" terdapat beberapa jenis pantun yaitu pantun muda-mudi, pantun orang tua, pantun teka teki, pantun rindu, pantun nasihat yang semuanya berjumlah 64 buah pantun. Pantun muda-mudi sebanyak 9 buah, pantun orang tua sebanyak 14 buah, pantun teka teki sebanyak 10 buah, pantun rindu sebanyak 15 buah, dan pantun nasihat sebanyak 16 buah. Pantun muda-mudi berfungsi sebagai sarana untuk berkenalan, mengungkapkan perasaan cinta dan perpisahan. Pantun orang tua berfungsi sebagai alat menyampaikan petuah baik dalam hal agama ataupun adat. Pantun teka teki berfungsi sebagai alat untuk menguji kepandaian pembaca dalam berfikir. Pantun rindu berfungsi sebagai alat menyampaikan perasaan rindu. Pantun nasihat berfungsi sebagai alat menyampaikan nasihat dan larangan. Pantun yang terdapat di dalam buku "Mantra Syair dan Pantun di Tengah Kehidupan Dunia Modern Karya Korrie Layun Rampan tahun 2014" memiliki kesamaan dengan pantun bahasa Indonesia baik jenis maupun ciri-cirinya. Pantun muda-mudi, pantun orang tua, pantun teka teki, pantun nasihat, dan pantun rindu terdiri atas empat 
baris dalam sebait, tiap baris terdiri atas 8-12 suku kata, bersajak a-b-a-b, dua baris pertama disebut sampiran dan dua baris berikutnya dinamakan isi.

\section{DAFTAR PUSTAKA}

Gani, Larik. 2007. Siaran Televisi Edukasi Bahasa Indonesia. Jakarta: Pusat Teknologi Informasi dan Komunikasi Pendidikan Departemen Pendidikan Nasional.

Kosasih, Engkos. 2013. Cerdas Berbahasa Indonesia. Jakarta: Erlangga.

Mahsun. 2011. Metode Penelitian Bahasa. Jakarta: PT Rajagrafindo Persada.

Rampan, Korrie Layun. 2014. Mantra Syair dan Pantun di Tengah Dunia Modern. Bandung: Yrama Widya.

Sugiarto, Eko. 2015. Mengenal Sastra Lama. Yogyakarta: C.V Andi Offse.

Waridah, Ernawati. 2014. Kumpulan Majas, Pantun, dan Peribahahasa Plus Kesusastraan Indonesia. Bandung: Ruang kata. 